\title{
Patterns of Moderate to Vigorous Physical Activities and daily Compliance with Guidelines for Youth
}

\author{
J. C. Ribeiro*, M. Sousa, C. Sá, P. Santos, P. Silva, L. Aires and J. Mota
}

Research Centre in Physical Activity Health and Leisure, Sports Faculty, University of Porto, Portugal

\begin{abstract}
Physical inactivity is a well-documented risk factor for coronary heart disease and it is associated with increased risk for several chronic diseases. Current health-related physical activity recommendations for youth call for at least $60 \mathrm{~min} \cdot \mathrm{d}-1$ of moderate-to-vigorous physical activities (MVPA) daily as part of their lifestyle. The aim of this study was to compare the compliance among boys and girls with 60 minutes of Moderate to Vigorous Physical Activities (60MVPA) daily. A random sample of 210 (12-18 years) boys and girls was evaluated from Porto region. The following measurements were carried out: weight, height, Body Mass Index (BMI), and PA levels (accelerometers). The study was conducted during 7 consecutive days. Our results showed that there was a difference in the compliance of 60MVPA between boys and girls, in both weekdays and weekend days $(\mathrm{p}<0.05)$. The compliance with PA guidelines for girls ranged between $19.4 \%$ (Saturday) and $70.6 \%$ (Friday) while in boys the data ranged between $47.7 \%$ (Sunday) and $84.6 \%$ (Friday). However, only $15 \%$ of boys and $7 \%$ of girls accomplished the 60MVPA criteria everyday.
\end{abstract}

Key Words: Physical activity, children, guidelines.

\section{INTRODUCTION}

Childhood obesity is linked to several risk factors associated with chronic diseases [1-3] that might be tracking into adulthood $[4,5]$. Thus, prevention of overweight and obesity in children seems to be the best way of preventing these adult diseases [6]. The preventive measures should be focus on those who are not yet overweight especially in the inactive children.

Moreover, despite evidence on the social, health, and personal benefits of physical activity, many people still choose not to exercise. The value of physical activity to normal growth and development, including the health and well being of children and adolescents is well established [7-9]. The health benefits of regular physical activity for children and adolescents include building and maintaining healthy bones, controlling weight, decreasing body fat, increasing muscle mass, decreasing blood pressure, and reducing anxiety and depression [9].

Accordingly, promoting physical activity and healthy lifestyles has become a public health priority worldwide. Furthermore, exercise or increasing physical activity is one of the cornerstones of pediatric obesity treatment, along with dietary and behavior change [10], and it is essential for children's current and future health [11].

Because of the growing awareness of the health benefits of regular physical activity, public health guidelines for physical activity have been established. Several of these guidelines focus on youth $[8,12,13]$, and current

*Address correspondence to this author at the Research Centre in Physical Activity Health and Leisure, Sports Faculty, University of Porto, Portugal, Rua Dr. Plácido Costa, 91, 4200450 Porto, Portugal; Fax: (0351)225 500 689; Tel: (0351) 225074 786; E-mail: jribeio@fade.up.pt recommendations call for at least $60 \mathrm{~min} \cdot \mathrm{d}-1$ of moderate-tovigorous physical activities, daily as part of their lifestyle.

Although different studies have addressed the question of the 60 MVPA accomplishments with regard different accelerometer cut-points $[14,15]$ epoch length $[15,16]$ and gender $[17,18]$, they mostly showed the percentage or prevalence of those whom accomplished that guideline. Despite that very little attention has been paid with regard the percentage of youth whom accomplished this guideline daily. As a matter fact most of the studies analyzed the total amount of weekly MPVA divided by the number of days monitored and assumed the accomplishment of weekly MVPA. However, PA showed a large variation across day $[17,19,20]$ and, therefore, differences in the compliance of guidelines accomplishment might be seen.

Thus, the aim of this study was to compare the compliance among boys and girls with the daily MVPA recommendations for youth.

\section{METHODS}

The sample was recruited from 3 different schools in Porto district, and consisted of 210 (12-18 years) boys (n, 80; age, $15.1 \pm 1.6$; weight, $62.4 \pm 14.3$; height, $168.6 \pm 11.1$; BMI, $21.7 \pm 3.6$ ) and girls (n, 130; age, $14.8 \pm 1.8$; weight, $53.7 \pm 9.5$; height, $159.1 \pm 6.6$; BMI, $21.2 \pm 3.3$ ), that were evaluated in schools premises, in classrooms and gym . Weight, percentage of fat mass (Tanita Inner Scan, model BC 532), waist circumference (WaistC), Heigth (Holtain Stadiometer) and PA levels (GT1M, ActiGraph, LLC), were evaluated in accordance with standard procedures. The activity monitor (GT1M) was used as instrument to objectively measure daily PA. Body Mass Index (BMI) was calculated from the children's height and weight [weight $(\mathrm{Kg}) / \mathrm{height}^{2}$ $(\mathrm{m})]$. Children and adolescents were classified in categories 
of BMI, as normal, overweight and obese, in accordance with internationally agreed procedures [21].

\section{Objective and Outcome Measures}

Physical activity was objectively measured for seven consecutive days using the GT1M accelerometer (ActiGraph, LLC, Pensacola, FL, USA). The students went trough the anthropometric evaluations, and in the same day was explained to children and adolescents how to use the accelerometer, and they were allowed to ask questions about all the procedures. The GT1M was initialized to start collecting data in the next day at 6.00AM, and researchers went back to school to collect them after 8 days, in order to assure the complete 7 days of evaluation. The use of this monitor to measure physical activity in children has been described previously [22-24]. Before each test period and for every child, the activity monitors were tested for updated firmware and battery life, during initialization of units. For the present study, the epoch duration or sampling period was set at 1 min. and the output was expressed as counts per minute (counts. $\min ^{-1}$ ). The accelerometer was placed in a small nylon pouch and firmly adjusted at the child's waist by an elastic belt over the non-preferred hip. A log was given to children's and their parents, and they were instructed to record the time when the monitor was attached in the morning and detached in the evening. They were also instructed to note every time the child performed any restricted activities like showering and swimming.

For the purposes of this study, only the total counts provided by the accelerometer were used in the analyses. Counts from the accelerometer were averaged to determine the mean count per minute for the intensity of each physical activity. Therefore, the physical activity variables were expressed in counts per minute (activity counts divided by minutes of monitored activity). The daily time spent in MVPA ( $>3$ MET) was calculated by summing the minutes of moderate, vigorous and very vigorous physical activities for each day. The age-specific count ranges corresponding to the intensity levels developed by Freedson et al. [25] were adopted. The gender and age-specific count ranges corresponding to the intensity levels were derived from the energy expenditure prediction equation $(\mathrm{r}=0.94$; standard error of the estimate $=1.19$ ) developed by Freedson et al. [26], for a pediatric population. This equation accounted for $90 \%$ of the variance in observed MET levels and predicted energy expenditure during treadmill running and walking within +1.1 METs. This procedure has previously been used in other populations [27] and similar cultural context [28].

\section{Statistical Procedures}

Means and standard deviations of the main variables, and the total time spent in MVPA were calculated For this analysis, we only considered MVPA because youth healthrelated PA guidelines stress health-related participation in MVPA. Differences in MVPA, daily and weekly, between genders were obtained with independent samples t-test. The chi-square test $\left(\chi^{2}\right)$ was used to determine the differences in the prevalence's in different days, and the amount of days with adherence to the guidelines. The level of significance was set at an alpha level of $\mathrm{p}<0.05$. Statistical analysis was performed using SPSS (Statistical Package for the Social Sciences) 15.0 for Windows (SPSS Inc, Chicago, IL).

\section{RESULTS}

The participants' characteristics are shown in Table $\mathbf{1}$. Regardless the time period considered (daily or weekly) boys were significantly $(\mathrm{p}<0.05)$ more physically active than girls. Additionally our data also showed that on average children were quite active.

Our results (Fig. 1) show that there's a difference in the adherence to 60MVPA between boys and girls, during nearly all the days of the week and weekend $(p<0.05)$.

When comparing results in the different days of the week, we can observe that in girls the percentage, meeting the guidelines for a day, fluctuate between $19.4 \%$ (Saturday) and $70.6 \%$ (Friday). When comparing boys we can look at values between $47,7 \%$ (Sunday) and $84.6 \%$ (Friday).

Table 1. Mean $(\bar{X})$ and Standard Deviation (SD) of Age, Weight, Height, Waist Circumference (WaistC), Body Mass Index (BMI), Moderate to Vigorous Physical Activities (MVPA; Weekly and Daily); Percentage of Normal Weight, Overweight and Obese Children, and Statistical Differences Between Genders (p value; "Independent Samples t-test; ${ }^{\#}$ Chi-square test)

\begin{tabular}{|c|c|c|c|c|c|}
\hline \multirow[t]{2}{*}{ Variables } & \multicolumn{2}{|c|}{ Boys } & \multicolumn{2}{|c|}{ Girls } & \multirow[t]{2}{*}{$\mathbf{p}$} \\
\hline & $\bar{X}$ & SD & $\bar{X}$ & SD & \\
\hline Weight $(\mathrm{Kg})$ & 62.4 & 14.3 & 53.7 & 9,5 & $0,000^{*}$ \\
\hline Height $(\mathrm{cm})$ & 168.6 & 11.1 & 159.1 & 6,6 & $0,000^{*}$ \\
\hline BMI $\left(\mathrm{Kg} / \mathrm{m}^{2}\right)$ & 21.7 & 3.6 & 21.2 & 3,33 & $0,249^{*}$ \\
\hline MVPA (min.week ${ }^{-1}$ ) & 624.7 & 243.3 & 428.4 & 403,5 & $0,000^{*}$ \\
\hline MVPA (min.day $\left.{ }^{-1}\right)$ & 89.2 & 34.8 & 61.2 & 27,7 & $0,000^{*}$ \\
\hline
\end{tabular}


Actually, when we analyze all children that accomplish the recommendations of 60MVPA during all days of the week (7 days) only $15 \%$ of boys and $7 \%$ of girls meet the criteria (Fig. 2). Interesting to note that if we only consider the adherence to the recommendations in 5 or more days during a week, boys would accomplish with $53.7 \%$ of the recommended guidelines, whilst girls achieve $24.6 \%$. On the other end if we consider those that didn't accomplish the guidelines in 3 or less days/week, $29.3 \%$ of boys and $60 \%$ of girls would be considered as inactive.

\section{DISCUSSION}

The main finding of this study was the estimates of the prevalence of compliance to activity guidelines ranged from 7,7\%-15\% (7 day; for girls and boys) to $24,6 \%$ (girls)-53,7\% (boys) for at least 5 days a week in MVPA, depending how

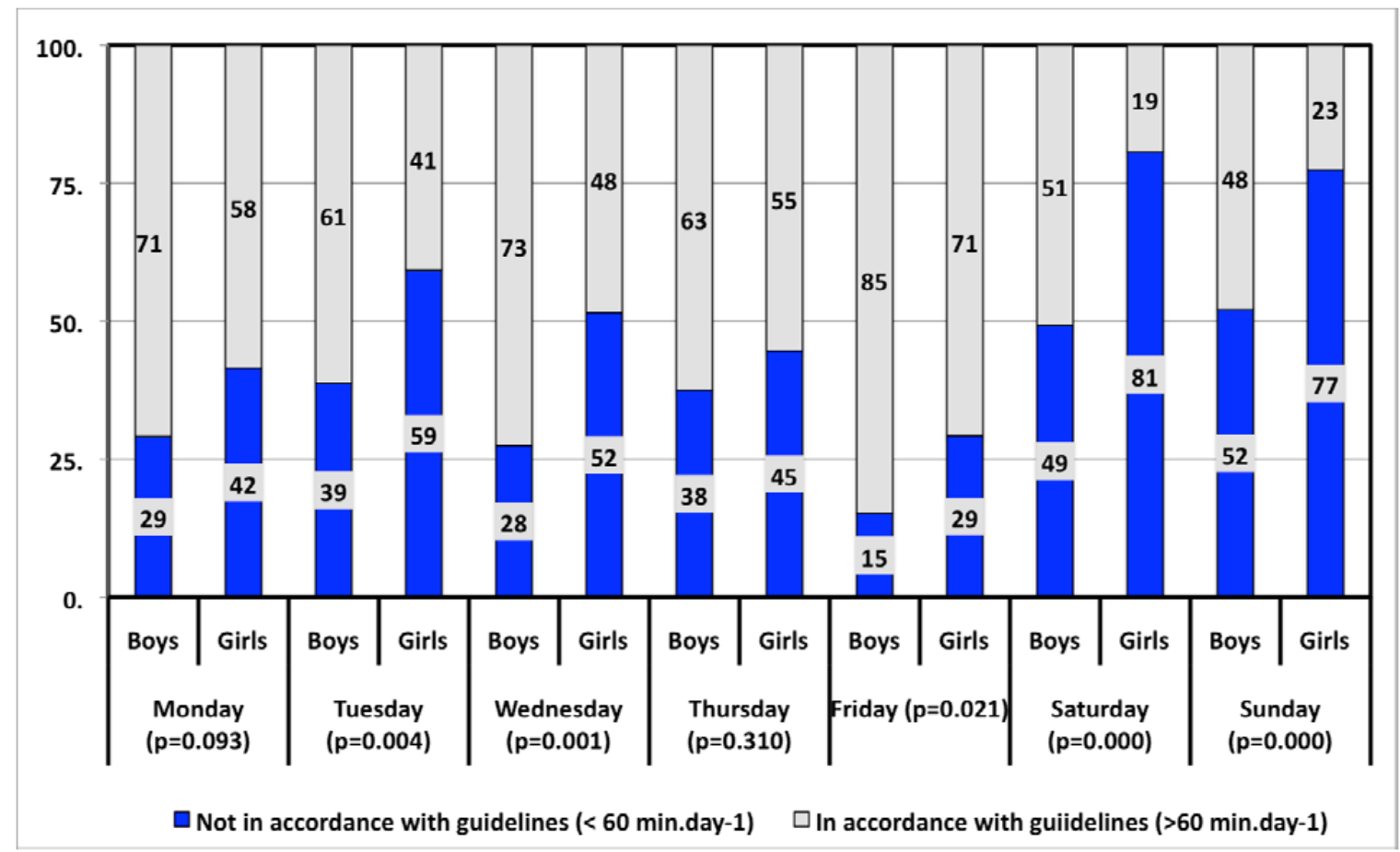

Fig. (1). Percentage of children compliant and not compliant with PA guidelines (60MVPA), by gender and days of the week. Differences between genders in each day of the week [chi-square test $\left(\chi^{2}\right)$ ].

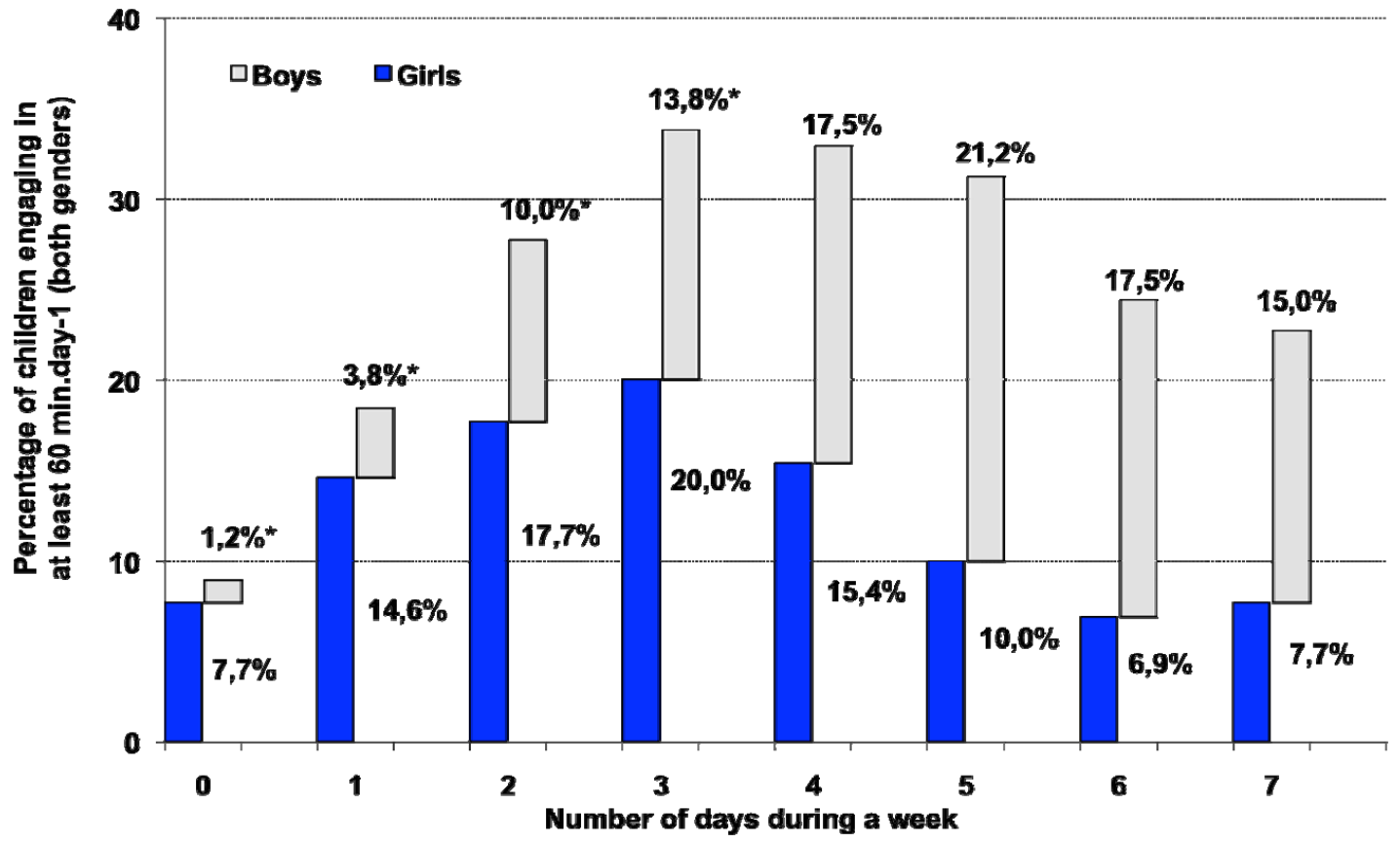

Fig. (2). Percentage of children that meet up with the PA guidelines (60MVPA) in different number of days by gender. *Significant differences between genders $[p<0.05$; chi-square test $(\chi 2)]$. 
the guidelines were interpreted. Similar results were observed by Olds et al. [29] in a sample of Australian children, where they found prevalence's of $20 \%$ in four complete days, but ranging from $20 \%-68 \%$, given that children were classified with significantly different compliance's by the different methods. In particular, only a very small proportion of children were compliant using the "All Days" method. The results from studies using different methods would therefore not be comparable, and predictors and correlates of compliance calculated using one method may no longer be significant when compliance is calculated by another method [29].

The decline in physical activity levels of young children seems to be combined with a high prevalence of obesity and overweight and a reduction in the participation in organized sport [30-32]. With the ever-increasing interest in exploring the relationship between physical activity and obesity amongst children, it is important to provide a more precise estimate of both physical activity and the compliance with PA guidelines.

Although several recommendations have been made recently aiming at increasing the levels of PA and the compliance with 60 or more minutes of MVPA [33], data from the 2005 Youth Risk Behavior Surveillance System demonstrated that only $35.8 \%$ of high school students met those current physical activity recommendations of 60 minutes of MVPA on 5 or more days per week [34].

In much the same way as internationally-agreed BMI cut-points represented a major advance without which secular trend and cross-country comparisons were impossible, some papers highlight how important consistency is when putting to practice physical activity guidelines for youth $[35,36]$.

The choice of method will certainly be flawed, but should nonetheless be agreed for these purposes. Future research must address the physical activity and inactivity criteria most closely associated with health and illness [29].

A recent review contributed considerably to the understanding of the effects of regular physical activity on children's health [37], however the evidence-based knowledge to formulate physical activity recommendations and guidelines for children is still controversial [38, 39]. Making recommendations, even without consensus, is relatively easy; achieving the recommendations is the most challenging task.

Although the small sample size, and the limitations of the use of accelerometers to evaluate specific aspects of PA patterns in this study, like cycling or muscular resistance training, it should be highlighted that to our knowledge there isn't much published results in children and adolescents in Portugal using accelerometers.

\section{CONCLUSIONS}

The prevalence of children and youth meeting the guidelines of 60MVPA for every days of a week is very small, although when comparing individually the days of the week we can find percentages between $19.4 \%$ (girls) and $84,6 \%$ (boys) in specific days of the week. There is uncertainty concerning the true prevalence of adherence to the recommendations with physical activity guidelines in Portuguese children and youth, a national representative sample is needed in order to establish several public health strategies aiming at increasing the compliance with physical activities guidelines.

Standard methodological procedures (measurement instruments) and protocols concerning the number of days needed for adherence to the recommended guidelines, all days of a week (7 days a week), or partially (most of the days of a week), is needed in order to assemble internationally observance of the suggested guidelines of MVPA.

\section{ACKNOWLEDGEMENTS}

Supported from:

MCTES/FCT: Project PTDC/DES-72424-2006

\section{REFERENCES}

[1] Bao W, Srinivasan SR, Valdez R, Greenlund KJ, Wattigney WA Berenson GS. Longitudinal changes in cardiovascular risk from childhood to young adulthood in offspring of parents with coronary artery disease: the Bogalusa Heart Study. JAMA 1997; 278(21): $1749-54$.

[2] Burke V, Beilin LJ, Simmer K, et al. Predictors of body mass index and associations with cardiovascular risk factors in Australian children: a prospective cohort study. Int J Obes (Lond) 2005; 29(1): 15-23.

[3] Dietz WH. Health consequences of obesity in youth: childhood predictors of adult disease. Pediatrics 1998; 101(3 Pt 2): 518-25.

[4] Choudhury P. Adolescent onset of adult metabolic diseases. J Indian Med Assoc 2005; 103(11): 630-1, 7.

[5] Rossner S. Childhood obesity and adulthood consequences. Acta Paediatr 1998; 87(1): 1-5.

[6] Gunnell DJ, Frankel SJ, Nanchahal K, Peters TJ, Davey SG. Childhood obesity and adult cardiovascular mortality: a 57-y follow-up study based on the Boyd Orr cohort. Am J Clin Nutr 1998; 67(6): 1111-8.

[7] Bailey DA, Albinson JG, Andrew GM. The growing child and the need for physical activity: children in Sport and Physical Activity. Baltimore, Maryland.: University Park Press 1976; pp. 81-93.

[8] Barlow SE. Expert committee recommendations regarding the prevention, assessment, and treatment of child and adolescent overweight and obesity: summary report. Pediatrics 2007; 120 (Suppl 4): S164-92.

[9] Hills AP, King NA, Armstrong TP. The contribution of physical activity and sedentary behaviours to the growth and development of children and adolescents: implications for overweight and obesity. Sports Med (Auckland, NZ). 2007; 37(6): 533-45.

[10] Epstein LH, Goldfield GS. Physical activity in the treatment of childhood overweight and obesity: current evidence and research issues. Med Sci Sports Exerc 1999; 31(Suppl 11): S553-S9.

[11] Council on Sports Medicine and Fitness and Council on School Health. Active healthy living: prevention of childhood obesity through increased physical activity. Pediatrics 2006; 117(5): 183442.

[12] Andersen LB, Harro M, Sardinha LB, et al. Physical activity and clustered cardiovascular risk in children: a cross-sectional study (The European Youth Heart Study). Lancet 2006; 368(9532): 299304.

[13] Boreham C, Riddoch C. The physical activity, fitness and health of children. J Sports Sci 2001; 19(12): 915-29.

[14] Dencker M, Andersen LB. Health-related aspects of objectively measured daily physical activity in children. Clin Physiol Funct Imaging 2008; 28(3): 133-44.

[15] Trost SG, McIver KL, Pate RR. Conducting accelerometer-based activity assessments in field-based research. Med Sci Sports Exerc 2005; 37(Suppl 11): S531-43.

[16] Rowlands AV, Stone MR, Eston RG. Influence of speed and step frequency during walking and running on motion sensor output. Med Sci Sports Exerc 2007; 39(4): 716-27.

[17] Troiano RP, Berrigan D, Dodd KW, Masse LC, Tilert T, McDowell M. Physical activity in the United States measured by accelerometer. Med Sci Sports Exerc 2008; 40(1): 181-8. 
[18] Trost SG, Pate RR, Freedson P, Taylor W, Dowda M, Sirard J. Age and gender differences in objectvely measured physical activiy in youth. Med Sci Sports Exerc 2001; 34(2): 350-5.

[19] Yamauchi T, Kim SN, Lu Z, et al. Age and gender differences in the physical activity patterns of urban schoolchildren in Korea and China. J Physiol Anthropol 2007; 26(2): 101-7.

[20] Jago R, Anderson CB, Baranowski T, Watson K. Adolescent patterns of physical activity differences by gender, day, and time of day. Am J Prev Med 2005; 28(5): 447-52.

[21] Cole TJ, Bellizzi MC, Flegal KM, Dietz WH. Establishing a standard definition for child overweight and obesity worldwide: international survey. BMJ 2000; 320(7244): 1240-3.

[22] Welk GJ, Schaben JA, Morrow JR, Jr. Reliability of accelerometrybased activity monitors: a generalizability study. Med Sci Sports Exerc 2004; 36(9): 1637-45.

[23] Brage S, Wedderkopp N, Franks PW, Andersen LB, Froberg K. Reexamination of validity and reliability of CSA monitor in walking and running. Med Sci Sports Exerc 2003; 35 (8): 1447-54.

[24] Trost SG, Morehouse S, Watson P, Ward DS, Riner W, Burke J. Validity of the computer science and application (CSA) activity monitor in children. Med Sci Sports Exerc 1998; 30 (40): 629-33.

[25] Freedson P, Pober D, Janz KF. Calibration of accelerometer output for children. Med Sci Sports Exerc 2005; 37(Suppl 11): S523-30.

[26] Freedson SP, Sirard J, Debold EP, et al. Calibration of a uniaxial accelerometer for estimating exercise intensity in children and youth. Med Sci Sports Exerc 1997; 29(Suppl): S45.

[27] Trost SG, Pate RR, Freedson PS, Sallis JF, Taylor WC. Using objective physical activity measures with youth: how many days of monitoring are needed? Med Sci Sports Exerc 2000; 32(2): 426-31.

[28] Bassett DR, Jr, Ainsworth BE, Swartz AM, Strath SJ, O'Brien WL, King GA. Validity of four motion sensors in measuring moderate intensity physical activity. Med Sci Sports Exerc 2000; 32(9 Suppl): S471-S80.
[29] Olds T, Ridley K, Wake M, et al. How should activity guidelines for young people be operationalised? Int J Behav Nutr Phys Activ 2007; 4: 43 .

[30] Watts K, Jones TW, Davis EA, Green D. Exercise training in obese children and adolescents: current concepts. Sports Med 2005; 35 (5): 375-92.

[31] Tolfrey K, Jones AM, Campbell IG. The effect of aerobic exercise training on the Lipid-Lipoprotein Profile of children and adolescents. Sports Med 2000; 29(2): 99-112.

[32] Owens S, Gutin B, Allison J, et al. Effect of physical training on total and visceral fat in obese children. Med Sci Sports Exerc 1999; 31(1): 143-8

[33] Pate RR, O'Neill JR. Summary of the American Heart Association scientific statement: promoting physical activity in children and youth: a leadership role for schools. J Cardiovasc Nurs 2008; 23(1): 44-9.

[34] Brener ND, Kann L, Garcia D, et al. Youth risk behavior surveillance--selected steps communities, 2005. MMWR Surveill Summ 2007; 56(2): 1-16.

[35] Armstrong N, Welsman JR. The physical activity patterns of European youth with reference to methods of assessment. Sports Med 2006; 36(12): 1067-86.

[36] Pate RR, Freedson PS, Sallis JF, et al. Compliance with physical activity guidelines: prevalence in a population of children and youth. Ann Epidemiol 2002; 12(5): 303-8.

[37] Strong WB, Malina RM, Blimkie CJ, et al. Evidence based physical activity for school-age youth. J Pediatr 2005; 146(6): 7327.

[38] Twisk JW. Physical activity guidelines for children and adolescents: a critical review. Sports Med 2001; 31(8): 617-27.

[39] Timmons BW, Naylor PJ, Pfeiffer KA. Physical activity for preschool children--how much and how? Can J Public Health 2007; 98 (Suppl 2): S122-34.

(C) Ribeiro et al.; Licensee Bentham Open .

This is an open access article licensed under the terms of the Creative Commons Attribution Non-Commercial License (http://creativecommons.org/licenses/by-nc/3.0/) which permits unrestricted, non-commercial use, distribution and reproduction in any medium, provided the work is properly cited. 